\title{
Comparative proteomics reveals complex insecticides-associated resistance mechanism of Culex pipiens pallens Coquillett
}

Chongxing Zhang ( $\sim$ chongxingzhang@aliyun.com )

Shandong Institute of Parasitic Diseases https://orcid.org/0000-0001-5529-6783

\section{Feng Miao}

Shandong Institute of Parasitic Diseases

\section{Qiqi Shi}

National Institute of Parasitic Diseases, Chinese Center for Disease Control and Prevention, Shanghai, China

\section{Peng Cheng}

Shandong Institute of Parasitic Diseases

\section{Tao Li}

Nanning MHelix ProTech Co., Ltd.

\section{Xiuxia Guo}

Shandong Institute of Parasitic Diseases

\section{Song Xiao}

Shandong Institute of Parasitic Diseases

\section{Maoqing Gong}

Shandong Institute of Parasitic Diseases

\section{Research article}

Keywords: Mosquito, Molecular resistance adaptations, Comparative proteomics, Culex pipiens pallens

Posted Date: August 1st, 2020

DOI: https://doi.org/10.21203/rs.3.rs-45444/v1

License: (c) (1) This work is licensed under a Creative Commons Attribution 4.0 International License. Read Full License 


\section{Abstract}

Background: Mosquito control based on chemical insecticides is considered as an important element in the current global strategies for the control of mosquito-borne diseases. Unfortunately, the development of insecticide resistance of important vector mosquito species jeopardizes the effectiveness of insecticide-based mosquito control. As opposed to target site resistance, other mechanisms are far from being fully understood.

Results: Susceptible strain of $C x$. pipiens pallen showed elevated resistance levels to after 25 generations insecticide-selected, through bioinformatics analysis allowed detecting 2,502 proteins, of which 1513 were differentially expression in insecticide-selected strains as compared to the susceptible strain. Finally, midgut differential expression protein profiles and 62 proteins were selected for verification of differential expression using parallel reaction monitoring strategy.

Conclusions Significant molecular resources were developed for $C x$. pipiens pallen potential candidates involved in metabolic resistance as well as those participating in lower penetration or sequestration of insecticide. Global protein profiles of change to three insecticide strains combined with midgut profiles revealed multiple insecticide resistance mechanisms operate simultaneously in resistant insects of $C x$. pipiens pallens. Future research that is targeted towards RNA interference on the identified metabolic targets such as cuticular, cytochrome P450s and glutathione S-transferase proteins could lay the foundation for a better understanding of the genetic basis of insecticide resistance in $C x$. pipiens pallen.

\section{Background}

Mosquitoes and mosquito-borne diseases continue to pose a huge public health burden worldwide, malaria, lymphatic filariasis, dengue, chikungunya, and west nile virus cause significant medical and economic impacts that disproportionately affect developing countries[1-4].

Since the 1950s, chemical insecticides have been massively used for controlling mosquito populations. However, long-term intensive and widespread overuse or misuse use of insecticides induced intense selection pressure that has led to the development and subsequent intensification of various genetically modulated resistance mechanisms in mosquitoes [5-7], and has resulted in mosquito-borne diseases on the rise and outbreaks of mosquito-related diseases in recent years[8, 9]. Today, with the widespread development of resistance in mosquitoes to the most commonly used insecticides, insecticide resistance was regarded as the most serious threat to the control of mosquitoes and mosquito-borne diseases[10]. Nowadays, vector control of mosquitoes remains crucial to reduce disease transmission, and has long been a critical part of the global strategy to manage mosquito-associated diseases, the application of chemical insecticides are the most important component in mosquitoes control[11], so, characterizing molecular mechanisms underlying resistance is a key step for improving resistance management strategies. 
Previous studies on the molecular mechanisms of insecticide resistance have been performed at the transcriptional level, cDNA microarray[12, 13], RNA-seq[14, 15], leading to exciting progress with regard to the transcriptional basis of insecticide resistance. Dramatic progress has been made in identifying targetsite insensitivity in mosquitoess, such as Anopheles gambiae[16-18], An. arabiensis[19], Aedes albopictus[20], Culex pipiens[18, 21]. Metabolic resistance usually involves detoxification enzymes has been reported worldwide, including cytochrome P450s (CYPs or P450s)[22-24], glutathione Stransferases (GSTs)[25], and UDP glucosyl-transferases (UGTs) [26]. To date, two main types of molecular mechanisms of mosquitoes insecticide resistance included target-site insensitivity and metabolic resistance are known in mosquitoes[22, 27]. Due to the large number of mosquito genes encoding detoxification enzymes[28-30] pinpointing those responsible for resistance remains challenging[31].

Proteins, as the primary functional molecules, the executor to perform the gene function in many different physiological processes, currently, large-scale expression profiling and screening for resistance-related proteins in mosquitoes are limited, two-dimensional gel electrophoresis (2-DE) proteomics[32, 33], and isobaric tags for relative and absolute quantification (iTRAQ)[34]. Today, with the advent of highly advanced proteomic platforms based on iTRAQ[35], such knowledge gap can be overcome by high throughput sequencing approaches, which can generates concomitantly protein expression, ultimately provides a direct insight into the activity of relevant proteins.

In the present study, iTRAQ labeling coupled with liquid chromatography/tandem mass spectrometric (LC$\mathrm{MS} / \mathrm{MS}$ ) analysis was used to determine changes in protein amounts associated with adaptation to three insecticides (the pyrethroid cypermethrin, the propoxur, and dimethyl-dichloro-vinyl-phosphate) from distinct chemical families in the susceptible mosquito $C x$. pipiens pallens. Results are discussed in regards of known and new putative adaptive mechanisms conferring insecticide resistance in mosquitoes, which improve our understanding of mechanisms developed by mosquitoes to resist insecticides.

\section{Results}

\section{Insecticide resistance levels}

After 25 generations of larval selection with the insecticides cypermethrin, propoxur and DDV, bioassays revealed a constitutive increased resistance of each selected strain to its respective insecticide as compared to the parental susceptible strain (Table 1). Resistance levels of the Cx_pro and Cx_ddv strains were moderate but significant ( 11.34 fold and 8.17 fold respectively). Although significant, the resistance level of the Cx_cym strain to cypermethrin susceptible was considerably higher ( 243.00 fold).

\section{Protein identification and differentially expressed proteins (DEP) screening}

A total of 2,502 protein were identified in two replicates of the LC-MS/MS experiments with a high confidence of peptide selection (FDR=0.01). Among them, 1513 protein obtained quantitative message, all the proteins were completed annotated with the accession number for each identified protein arranged 
by the Gene Ontology, KEGG pathway, Domain, Cluster of Orthologous Groups (COG) function catalogues and Subcellular Location analyses (Additional file 1: Table S1). Our analysis revealed significant changes in proteins in these Cx_cym, Cx_pro, Cx_ddv, and Cx_s strains, there were 164 proteins with significant differential expression (fold change $>1.2$ and $p$ value $<0.05$ ) between the $\mathrm{Cx}$ _cym and $\mathrm{Cx}$ _s control groups, including 54 up-regulated and 110 down-regulated proteins. 156 proteins changed dynamically between the Cx_pro and Cx_s control groups, including 59 up-regulated and 97 down-regulated proteins, whereas 81 proteins changed between the Cx_ddv and Cx_s control groups, with 31 up and 50 downregulated proteins, respectively.

\section{Bioinformatics analyses of the altered proteins}

To better understand the characteristics of the altered proteins in response to insecticide selection, GO ontology was performed to analyze the upregulated and downregulated proteins among Cx_cym, Cx_pro, Cx_ddv, and Cx_s strains of $C x$. pipiens pallens (Figure 1). As shown, the most enriched GO terms regarding molecular function of the upregulated proteins were related to the structural constituent of cuticle, structural molecule activity, lipid transporter activity, chitin binding, transferase activity, transferring acyl groups and odorant binding, which had a higher fold enrichment (log2) and Fisher's exact test $p$-value $(-\log 10)$. Whereas with the downregulated proteins, structural constituent of cuticle were the most enriched GO terms.

Hierarchical clustering was employed to characterize changes in the Cx_cym, Cx_pro, Cx_ddv, and Cx_s strains, all quantified proteins were classified into 7 clusters based on their expression level, revealed clearly distinguishable increasing or decreasing expression (Figure 2). In KEGG enrichment analysis, drug metabolism - cytochrome P450 (map00982) and metabolism of xenobiotics by cytochrome P450 (map00980) pathways exist in response to insecticide selection conditions, implicating P450s are the important regulatory enzyme associated with metabolic resistance in $C x$. pipiens pallens under insecticide selection. Furthermore, the differential changes in glutathione S-transferase (B0W6D0), microsomal glutathione s-transferase (B0X075) and glutathione-s-transferase theta (B0XGK3) proteins in both pathways suggest a critical regulatory role associated with $\mathrm{P} 450$, these findings indicate that glutathione S-transferase may play an important role in the regulation of metabolic resistance pathway in Cx. pipiens pallens (Figure 3A and Figure 3B).

The KEGG pathways annotation of comparison shows that oxidative phosphophrylation (map00190) (Additional file 2: Figure S1) is activated associated with electron-transport chain subunits (Ndufa2, Ndufa4, Ndufa5, Ndufa7, Ndufa8, Ndufa9, Ndufab1, COX5), ribosome (03010) (Additional file 2: Figure S2) is activated associated with S15e, L34e, S6e, and L18Ae, respectively. Interestingly, those subunits quantitation deviated simultaneously towards different direction, such as Ndufs4, Ndufs decrease while Ndufa4 increase, in agreement, oxidation phosphorylation and membrane located proteins are critical nodes in glycolytic flux and transit intracellular signal avoiding malfunction.

Comparing the pattern of expression of different proteins among Cx_cym, Cx_pro, Cx_ddv, and Cx_S strains of $C X$. pipiens pallens, all of these proteins are significantly differentially expressed in resistant 
strains when compared to their expression in the susceptible strain, almost all protein enrichment changes at the peak and the lowest valley were in Cx_cym, Cx_pro and Cx_ddv, indicating that most of these protein showed an increase or decrease in expression following the insecticides selection from susceptible to resistance strains in $C x$. pipiens pallens, the insecticide selection alters the normal developmental pathway into an alternative one (Figure 4).

In Cx_cym vs. Cx_s, upregulated proteins, TGS-like, OBG-type guanine nucleotide-binding (G) domain, GTP binding domain, MD-2-related lipid-recognition domain, Beta-grasp domain, Chaperonin Cpn60/TCP-1 family, whereas downregulated proteins, Chitin-binding type R\&R consensus, Insect cuticle protein, Actin, conserved site, actin/actin-like conserved site, actin family, vitellinogen, open beta-sheet. In Cx_pro vs. Cx_s, upregulated proteins, FAD dependent oxidoreductase, chitin binding domain, serine proteases, trypsin family, serine active site, Serine proteases, trypsin family, histidine active site, Peptidase S1A, chymotrypsin family, whereas downregulated proteins, Insect cuticle protein, Chitin-binding type R\&R consensus, Actin, conserved site, Actin/actin-like conserved site, Actin family, Vitellinogen, open betasheet. In Cx_ddv vs. Cx_s, upregulated proteins, Immunoglobulin E-set, Ribosomal protein L30, ferredoxinlike fold domain, ribosomal protein L30, conserved site, chitin-binding type R\&R consensus, hemocyanin, $\mathrm{N}$-terminal, whereas downregulated proteins, insect cuticle protein, chitin-binding type R\&R consensus, adult cuticle protein 1, insect odorant-binding protein A10/ejaculatory bulb-specific protein 3 (Figure 5).

\section{Prediction of the PPI network under insecticide selection}

Because the protein-protein interaction plays important roles in most cellular biological processes, the PPI network were predicted under insecticides selection conditions using the STRING (www.string-db.org) online PPI prediction software, to further analyze the functional correlation of differentially expressed proteins between each group (Figure 6, Additional file 2: Figure S3-S4).

\section{Validation of proteomics data by parallel reaction monitoring}

To validate the accuracy and reproducibility of the proteomics analysis results, parallel reaction monitoring (PRM)-quantifiable strategy analyses were performed, 65 proteins selected as those that may play important roles in pyrethroid resistance, the differentially expressed levels of these proteins were quantified in $\mathrm{Cx} \_$cym, Cx_pro, Cx_ddv and $\mathrm{Cx}$ _s strains of $C x$. pipiens pallens were verification and validation, all proteins, peptides, and measured peptide peak areas are listed (Additional file 3: Table S2).

Differential protein expression in the midgut of $C x$. pipiens pallen induced by Bti

A total of 564 protein were identified with 559 protein obtained quantitative message, there were 66 proteins with significant differential expression (fold change $>1.2$ and $p$ value $<0.05$ ) between the Cx_bti and Cx_nbti control groups, including 33 up-regulated and 33 down-regulated proteins (Additional file 4). Most of the proteins coding for cuticular, cytoskeleton related proteins, metabolic enzymes are enrichment differential changes in the digestive tract linings dissected from Cx_bti strain of $C x$. pipiens pallens (Additional file 2: Figures S5-S8). Given our interest in the role of P450s in metabolic resistance, 
we further profiled the differential protein expression of Cytochrome P450 3A19 (B0X758) in the midgut of third instar larvae of $C x$. pipiens pallen, P450 protein showed higher expression levels in Cx_bti strains.

\section{Discussion}

$C x$. pipiens pallenst is the primary vector of the Japanese encephalitis virus and filariasis in China, that has developed resistance to several insecticides used for mosquitoes control. To date, the lack of genomics data available for this species has hampered characterisation of the molecular mechanisms underlying resistance. A profound understanding of the molecular mechanisms regulating insecticides resistance and development may aid in the control of this mosquitoes by facilitating the development of more sustainable and environmentally-friendly approaches. In this study, the proteomics of three distinct chemical families insecticides selected strains (the Cx_cym, Cx_pro, Cx_ddv groups) and susceptible strain of mosquitoe $C x$. pipiens pallens were compared.

The insect cuticle, also known as the exoskeleton, is the outermost part of the insect body, it serves a variety of functions such as sensory perception of the environment, means of locomotion[36], maintain the physical structure of the organism, the foregut, hindgut, tracheal system and apodemes[37], and protection from desiccation, moreover, the cuticle also serves as the first and major barrier against external adverse compounds penetration[38]. So, the cuticle is a major route of insecticide penetration in insects, insect cuticles are composed of cuticular protein, chitin and lipids, in fact, the properties of insect cuticle including permeability to pyrethroids are influenced not only by the chitin sclerotization, construction, and hydration, but also by the regular combinations of different cuticular proteins and their arrangements[38,39], recent protein-level and gene-level analyses have demonstrated a surprising diversity of cuticular proteins within and amongst species[40].

In previous studies, some cuticle genes have been identified overexpressed in pyrethroid resistant strains of several mosquito species in An. stephensi[41], An. funestus [14] and CX. pipiens pallens[34] and bed bug, Cimex lectularius[39, 42, 43]. The abundance of the protein in limb cuticle correlates nicely with the > 2 -fold increased abundance of their transcript in pyrethroid resistance An. gambiae[44]. The uptake of organophosphate can be reduced by a thickening or a change in the chemical composition of the cuticle in organophosphate-resistant strains of Culex quinquefasciatus[45] and Culex tarsalis[46], pyrethroid resistant An. funestus and An. gambiae do indeed have thicker cuticle than sensitive forms[37, 47], in the German cockroach, Blattella germanica decreased penetration of labeled insecticides in (1R)-transpermethrin-selected strain of the housefly and fenvalerate resistance [48, 49], low level of cross resistance to many insecticides observed in the An. stephensi strain might be partially explained by reduced penetration[50], the epicuticle hydrocarbon lipids were enriched in pyrethroid resistance An. gambiae[51] and An. arabiensis[52] female mosquitoes.

Our experiments indicate that GO terms representing proteins of structural constituent of cuticle, structural molecule activity, chitin binding proteins were affected by insecticide selection in $C x$. pipiens pallens, as a relatively large number of cuticle-associated proteins with a diversity of functions showed 
highly differential abundance in cypermethrin resistant strain, propoxur resistant strain, DDV resistant strain and susceptible strain (Fig. 1). And in our study, chitin-binding type R\&R consensus, insect cuticle protein, actin, conserved site, actin/actin-like conserved site, and actin family were enriched domains for downregulated proteins in Cx_cym vs. Cx_s. In Cx_pro vs. Cx_s, chitin binding domain was upregulated proteins, whereas insect cuticle protein, chitin-binding type R\&R consensus, actin, conserved site, actin/actin-like conserved site, actin family were downregulated proteins, respectively. In Cx_ddv vs. Cx_s, the enriched upregulated proteins was ferredoxin-like fold domain, chitin-binding type R\&R consensus, whereas downregulated proteins were insect cuticle protein, chitin-binding type R\&R consensus, adult cuticle protein 1(Fig. 5).

Change of cuticular protein determines the cuticle composition and performance is the basis for explaining the performance of cuticle-based insecticide resistance. Therefore, other alterations of cuticle structure and composition such as cuticular remodelling may be also involved in cuticular resistance. Taken together, our observations confirm the notion that cuticle proteins show altered expression and cellular cytoskeletal rearrangement, suggesting fortification of structural components in response to insecticide selection and leading to increased insecticide resistance in $C X$. pipiens pallens. Although how cuticle proteins are involved in the process of cuticle alterations for slowing down the penetration of insecticides is puzzling, this result provides useful information for us to conduct further studies on the cuticular protein and cuticle.

Metabolic resistance occurs via subtle alterations in either the protein levels or the activity of detoxification enzyme that resist insecticides[53, 54], such as P450s, glutathione S-transferases (GSTs), P450s possess catalytic roles in the metabolism of many essential endogenous molecules, and allows insects to metabolize insecticides at a higher rate [31,55], up- or down-regulation of P450 genes may be responsible for the detoxification of insecticides and the homeostatic response of mosquitoes to changes in cellular environment [56]. Cx. pipiens pallens, like most insect species, metabolises xenobiotics such as insecticides using a suite of detoxification enzymes, in this study functional annotation of cytochrome P450 role was identified by proteomic studies directly, several detoxification proteins cytochrome P450 (B0XDA9), cytochrome P450 3A19(B0 × 758), cytochrome P450 4g15 (BOWQV0, B0XHB7), cytochrome P450 9b1 (B0W6Y4), cytochrome P450 monooxygenase CYP9M10 (E5E7H3) and cytochrome P450 12b1 (BOWTS3) have been identified that are differentially expressed in insecticide resistant populations in $C X$. pipiens pallens. In this study, P450 proteins whose expression levels changed significantly belonged primarily to the different families. In addition, data from many other studies are highlighting a key role for P450 in insecticide detoxification in Anopheles funestus [14], Culex quinquefasciatus [57, 58]. Elevated levels of P450 activity are frequently observed in pyrethroid-resistant malaria vectors in Africa [59-67], in line with other insect pests such as the whitefly[68] and cockroach [69], over-expression of cytochrome P450s contribute to resistance to neonicotinoid insecticides in the hemipterans Bemisia tabaci and Myzus persicae [70, 71]. Furthermore, it has been suggested that these elevated P450s also confer crossresistance to carbamates[60]. 
Beyond insecticide metabolism and resistance, P450 enzymes playing essential roles in hormone metabolism or cuticular hydrocarbon synthesis[72]. Recently, the P450 enzyme responsible for the oxidative decarbonylation of long-chain fatty aldehydes[73] was shown to be a member of the CYP4G subfamily[74], which are restricted to insects, with clearly identifiable sequence peculiarities[74], interesting, in this present study, cytochrome P450 4g15 (BOWQV0, B0XHB7) right belong to CYP4G family.

In this study, proteomics sequencing from larvae exposed to insecticides (cypermethrin, propoxur and DDV) has confirmed the cross-induction of detoxification enzymes by insecticides, that is, not with particular P450s induced by xenobiotics, otherwise, detoxification enzymes glutathione S-transferase 1 (BOWQW9, BOXAJ0), glutathione S-transferase 1-1 (BOXGJ8, B0XGK1), glutathione S-transferase (BOVZ90, BOW6D0), glutathione-s-transferase theta (BOXGJ5, B0XGK0, BOXGK3), glutathione synthetase (BOWSC1), glutathione transferase class-sigma-like protein (D3KST8), and glutathione transferase (C4B4V7, C4B4V8) were also identified in was identified differentially expressed in Cx. pipiens pallens. Furthermore, the differential expression in glutathione S-transferase (BOW6D0), microsomal glutathione s-transferase $(\mathrm{BO} \times 075)$ and glutathione-s-transferase theta $(\mathrm{BOXGK3})$ enzyme in metabolism of xenobiotics by cytochrome P450 (Fig. 3A) and drug metabolism - cytochrome P450 pathways (Fig. 3B) suggest a critical regulatory role associated with P450, however, the contribution these GSTs enzymes make towards insecticides resistance and their biochemical relationships with P450-mediated resistance is still unclear.

The tissue specific expression of a protein normally is related to its function in that tissue[75], the functional significance of the digestive tract linings in regards to $C X$. pipiens pallens is especially important, all these tissues contain epidermis and cuticle, as the digestive tract lining constitutes the major part of their body, when $C x$. pipiens pallens larvae come in contact with or consume insecticides, they may develop resistance by modification in the insect cuticle or digestive tract linings that prevent or reduce the rate of penetration. In this study, cuticular, cytoskeleton related proteins are enrichment differential expressions in the digestive tract linings compared from $\mathrm{Cx}$ _bti strain of $\mathrm{Cx}$. pipiens pallens (Additional file 3, Additional file 4: Figures S5-S8), higher levels of proteins when compared to the levels were detected for cytochrome P450 3A19 (B0 × 758) of the midgut in Cx_bti vs. Cx_nbti, suggesting a potential role in metabolic resistance of $\mathrm{P} 450$. Once insecticide enters the $C x$. pipiens pallens larvae, enhanced metabolic detoxification could decrease the concentration of insecticides before they reach the target site, the midgut-associated $C x$. pipiens pallens $\mathrm{P} 450$ s consistent with their role in xenobiotic metabolism.

\section{Conclusions}

In summary, these results significantly increase the molecular resources available for the study of mosquitoes and we have identified several candidate proteins potentially involved in different phases of insecticide metabolism as well as those participating in other modes of insecticide resistance in $C x$. pipiens pallens. Significant differentially expressed proteins across biologically variant samples were 
revealed by iTRAQ proteomics approach. Specifically, the high occurrence of differential expression cuticular, cytoskeleton related proteins, and the expression patterns of P450s in midgut(cuticular) tissue support previous studies suggesting represent unique sites for penetration resistance (cuticle) as well as metabolic resistance (P450s) in Cx. pipiens pallens.

A common phenomenon of insecticide resistance is that multiple mechanisms operate simultaneously in resistant mosquotes of $C x$. pipiens pallens. Typically, a combination of diverse mechanisms provides significantly higher levels of resistance than one individual mechanism. In addition it has provided further support for the role of P450 genes in insecticides resistant while suggesting that other gene families such as cuticular genes could also be involved. Future functional studies on cuticular and P450s proteins could lay the foundation for identifying hot-spots for insecticide resistance in $C x$. pipiens pallens, which could provide the basis for developing effective management strategies.

\section{Methods}

\section{Mosquito selection with insecticide and larvicidal bioassay}

The laboratory Tangkou strain of $C x$. pipiens pallens, originating from Tangkou Village (Jining prefecture, Shandong Province), has been colonized in standard insectary conditions without exposure to any insecticides since 1960 , fully susceptible to insecticides, all the susceptible mosquito populations were reared at a constant room temperature of approximately $28{ }^{\circ} \mathrm{C}$ and $75 \%$ relative humidity with a photophase of $14 \mathrm{~h}$ and a scotophase of $10 \mathrm{~h}$, adult mosquitoes were provided with $10 \%$ sugar solution, was used as a parental strain to repeatedly selected for 25 generations to produce three independent resistant strains at the larval stage with the pyrethroid insecticide (cypermethrin), the carbamate insecticide (propoxur) and the organophosphates insecticide (DDV) at the median lethal concentration (LC50)[34], a detailed selection procedure was described previously[76, 77]. Technical-grade formulations of cypermethrin, propoxur and DDV were employed for the larval bioassay study, different concentrations of these insecticides were prepared using denatured alcohol as solvent $(98 \mathrm{ml}$ of absolute alcohol $+2 \mathrm{ml}$ of methyl ethyl ketone) as described by Shetty [78].The cypermethrin, propoxur and DDV selected strains were defined as cypermethrin-resistant (Cx_cym), propoxur-resistant (Cx_pro) and DDV-resistant (Cx_ddv) strains.

For validation of differently protein expression in the midgut of $C x$. pipiens pallen, larvae were reared in round plastic tubs (diameter $0.6 \mathrm{~m}$ ) filled with water with fish food twice daily, experimental larvae were randomly collected from several tubs to compensate for size differences and feeding history which are known to be influenced by larval density, all laboratory experiments were carried out with third instar larvae of laboratory-reared, 50 third instar larvae were exposed for $5 \mathrm{~h}$ to $0.021 \mathrm{mg} / \mathrm{l}$ of Bacillus thuringiensis var. israelensis (Cx_bti, Shandong Lukang Sheryl Pharmaceutical Co., Ltd, 3000 ITU/mg), the dosage following the standard testing procedures for microbial tests [79], we chose a $5 \mathrm{~h}$ treatment time to allow larvae to ingest the Bacillus thuringiensis var. israelensis without severely affecting their behavior and without causing evident damage to the intestinal tissue at the microscopic histological 
level. In the control group (Cx_nbti), larvae were exposed to water under the same conditions. Larvae exposed to the insecticide were washed in water and midgut pools were dissected and transferred to 1.5$\mathrm{mL}$ microcentrifuge tubes containing $1 \mathrm{~mm}$ phenylmethylsulfonyl fluoride (PMSF) and stored at $-80{ }^{\circ} \mathrm{C}$ before use.

\section{Extraction of protein and proteolysis}

Each sample (the Cx_cym, Cx_pro, Cx_ddv and Cx_s strains) were extracted separately from 5 egg rafts, 5 fourth-instar larvae, 5 pupae, 2-3 days old 5 adult males, 5 adult females (without blood feeding) and midgut pools. Briefly, each samples were completely homogenized in protein extraction buffer ( $8 \mathrm{M}$ urea, 2 mM EDTA, $10 \mathrm{mM}$ dithiothreitol (DTT) and 1\% Amresco Protease Inhibitor Cocktail), then samples were lysed at room temperature for 3 min of sonication, and centrifuged for 10 min at $13000 \mathrm{rpm}$, the supernatants was subjected to precipitated with chilled acetone for $3 \mathrm{~h}$ at $-20^{\circ} \mathrm{C}$. The resulting protein concentration of each sample was measured using Bradford Protein Assay Kit. Then, a total of $100 \mu \mathrm{g}$ protein/sample was combined from egg, larvae, pupae, adult male and female stage (each for $20 \mu \mathrm{g}$ ), reduced with $10 \mathrm{mM}$ DTT for $60 \mathrm{~min}$ at $37^{\circ} \mathrm{C}$, followed by adding $25 \mathrm{mM}$ iodoacetamide (IAA) to each protein samples, then alkylation by $45 \mathrm{~min}$ in darkness at room temperature, subsequently, $100 \mathrm{mM}$ tetraethylammonium bromide (TEAB) was added to reduce the concentration of urea to $<2 \mathrm{M}$. Finally, samples were digested with trypsin (enzyme-to-substrate ration of 1:50) overnight at $37^{\circ} \mathrm{C}$, and an additional second digestion was done for $4 \mathrm{~h}$ to ensure complete cleavage.

After trypsin digestion, each peptides samples desalting was performed by using Strata X SPE column, dried, and re-suspended in $25 \mu \mathrm{L} 500 \mathrm{mM}$ TEAB and labeled with 8-plex iTRAQ kit. Each dried and labeled peptide sample was reconstituted by using HPLC solution $\mathrm{A}(2 \% \mathrm{ACN}, \mathrm{pH} 10)$ and fractionated by high-pH reverse-phase HPLC on a Waters Bridge Peptide BEH C18 (130 ̊, $3.5 \mu \mathrm{m}, 4.6 \times 250 \mathrm{~mm})$. Loaded peptides were eluted with $2 \%$ to $98 \%$ acetonitrile gradient buffer solution at $\mathrm{pH} 10$ in 60 fractions at a speed of 0.5 $\mathrm{ml} / \mathrm{min}$ over $88 \mathrm{~min}$. A total of 20 fractions were combined and each fraction was desalted by using Ziptip C18 (Merck Millipore, Ziptip Pipette Tips 10 1 L). Samples fractions were dried on vacuum concentrator and stored at $-20{ }^{\circ} \mathrm{C}$ pending MS analyses.

\section{High-resolution LC-MS/MS analysis}

LC-MS/MS experiments were performed on a NanoLC 1000 LC-MS/MS liquid chromatography system (Thermo) equipped with a Proxeon EASY-nLC 1000 coupled to LTQ-Orbitrap Elite. Briefly, peptides were acidified in $0.1 \%$ formic acid, were trapped in a $3 \mu \mathrm{m} 100 \AA$ Acclaim PepMap $® 100 \mathrm{C} 18$ (Thermo) $75 \mu \mathrm{m} \times 2$ $\mathrm{cm}$ in $100 \%$ solvent $A(0.1 \mathrm{M}$ acetic acid in water), at a flow rate of $5 \mu \mathrm{L} / \mathrm{min}$ was used. Then, the analytical separation was performed on $2 \mu \mathrm{m} 100 \AA ̊$ Acclaim PepMap® RSLC C1850 $\mu \mathrm{m} \times 15 \mathrm{~cm}$ using a linear gradient of solvent B ( $98 \%$ ACN with $0.1 \%$ formic acid). The gradient ran at a flow rate of $250 \mathrm{~nL}$ /min as follows: $0-60$ min from $10 \%$ to $35 \%$ solvent B, $35 \%$ to $50 \%$ in $10 \mathrm{~min}$ and ramping to $100 \%$ solvent B. Mass spectrometry was operated in a data-dependent mode, automatically switching between MS and MS/MS (at mass range of $\mathrm{m} / \mathrm{z} 350$ to 1800 and resolution of 60,000 ) using repetitively full MS spectra scans followed by collision induces dissociation (HCD, at 38 normalized collision energy). The 20 most 
intense precursors were selected for subsequent decision tree-based ion trap HCD fragmentation in the MS survey scan and the following settings were used: collision energy: $38 \%$ above threshold, ion count: 300 with 30.0s dynamic exclusion. Full width at half maximum (FHMW) at $400 \mathrm{~m} / \mathrm{z}$ using an AGC setting of $1 \mathrm{e} 6$ ions, fixed first mass was set as $100 \mathrm{~m} / \mathrm{z}$.

\section{Mass spectrometry data analysis}

The mass spectrometry MS/MS raw data were searched against all Culex quinquefasciatus protein in the Culex Taxonomy database, downloaded from Uniprot Database using Sequest software integration in Proteome Discoverer (version 1.3, Thermo Scientific) with the following parameters: mass tolerance set to 20 ppm, product ion tolerance set to $0.02 \mathrm{Da}$, only trypsin sequences allowed. Oxidation, and protein $\mathrm{N}$ terminus acetylation were accepted as variable modifications and carbamidomethylation was accepted as static modification, a maximum of two miscleavages was permitted, peptide- and protein-level false discovery rates (FDRs) were filtered to $1 \%$.

\section{Functional classification of proteins}

Functional annotation and classification of all identified proteins were determined by using the Blast2GO program against the non-redundant NCBI protein database. The gene function databases complied for the Gene Ontology (GO), the Kyoto Encyclopedia of Genes and Genomes (KEGG) pathways, and Cluster of Orthologous Groups ( $\mathrm{COG}$ ) of proteins were used to infer putative functions of identified proteins. Detailed information can be found on http://www.geneontology.org. Significant GO terms $(p<0.05)$ were mapped with the REViGO online tool (http://revigo.irb.hr), which removes redundant GO terms and visualizes the semantic similarity of remaining terms[80]. KEGG Pathway is part of the Kyoto Encyclopedia of Genes and Genomes (KEGG) database, which is a reference database for pathway mapping, for KEGG Pathway analyses, the main biochemical metabolism and signal transduction pathways of identified proteins were extracted using the Search pathway tool in the Kegg Mapper platform (http://www.genome.jp/kegg/mapper.html)[81-83]. COG is the database for orthologous protein classification. Identified proteins were compared with the COG protein database to predict the function of proteins and conduct statistical analyses.

\section{Functional enrichment, protein expression pattern and function clustering}

Enrichment statistics of GO, KEGG pathway and Domain was done using Fisher's exact test, correction for multiple hypothesis testing was carried out under standard false discovery rate control methods and the pathways with a corrected $p$ value $<0.05$ were considered as the most significant pathways.

Expression-based and functional enrichment-based clustering for different protein groups was used to explore potential relationships between different protein groups at special protein function. Firstly, we collated all the protein groups obtained after functional enrichment analysis along with their $P$ values. Secondly, we sorted those categories enriched in at least one of the protein groups with a $P$ value $<0.05$. This filtered $P$ value matrix was transformed by the function $x=-\log 10$ ( $P$ value). Thirdly, $z$-transformed 
applies on $\mathrm{x}$ values for each functional category and $\mathrm{z}$ scores were clustered by one-way hierarchical clustering (Euclidean distance, average linkage clustering). Finally, cluster membership was visualized by a heat map using the "pheatmap" function from the R-package. Prediction of proteine-protein interaction (PPI) was done using the STRING database (version 10.0) and visualized using Cytoscape software (version 3.4.0) [84, 85].

\section{Parallel reaction monitoring analysis}

A label-free targeted parallel reaction monitoring (PRM) method[86] was adopted to verify the reliability of our label-based proteomics. A total of 62 differentially expressed proteins, including one internal standard housekeeping protein, were chosen. For the Cx_cym, Cx_pro, Cx_ddv and Cx_s strains, equal amounts of protein samples were analyzed for semi-quantitative measurements, and each strain underwent three replications. Peak areas were extracted from PRM mass spectrum data using Skyline software[87].

\section{Declarations}

\section{Ethics approval and consent to participate}

All animal experiments were carried out in accordance with the Animal Protection Law of the People's Republic of China and with the approval of the Ethical Committee of Shandong First Medical University \& Shandong Academy of Medical Sciences (Jinan, Shandong).

\section{Consent for publication}

All authors have given consent for publication.

\section{Availability of data and materials}

All data generated or analyzed during this study were included in this published article and its additional files.

\section{Competing Interests}

Author Tao Li was employed by the company Nanning MHelix ProTech Co., Ltd., the remaining authors declare that the research was conducted in the absence of any commercial or financial relationships that could be construed as a potential conflict of interest.

\section{Funding}

The present study was supported by the National Natural Science Foundation of China (NSFC) (Grant No. 8187168), Academic promotion programme of Shandong First Medical University (2019QL005) and the development of medical science and technology project of Shandong Province (2018WS302). The funders had no role in study design, data collection and analysis, decision to publish, or preparation of the manuscript. 


\section{Authors' contributions}

ZCX and GMQ conceived and designed the experiments. MF contributed reagents/materials/analytic tools. SQQ and CP performed the experiments. LT collected and analysed the data. GXX and SX analysed the data. ZCX wrote the paper. MF helped review and edit the final paper. All authors read and approved the final manuscript.

\section{Acknowledgements}

We thank Kai Yu of Shanghai MHelix BioTech Co., Ltd. for their assistance with experiments, we also thank Haifang Wang (Shandong Institute of Parasitic Diseases) for their assistance with insect rearing.

\section{References}

1. Lounibos L. Invasions by insect vectors of human disease. Annu Rev Entomol. 2002;47:233-66.

2. Bhatt S, Gething PW, Brady OJ, Messina JP, Farlow AW, Moyes CL, Drake JM, Brownstein JS, Hoen AG, Sankoh O, Myers MF, George DB, Jaenisch T, Wint GR, Simmons CP, Scott TW, Farrar JJ, Hay SI. The global distribution and burden of dengue. Nature. 2013;496(7446):504-7.

\section{WHO (2014) World Malaria Report 2014 (World Health Organization, Geneva) Available at} www.who.int/malaria/publications/world_malaria_report2014/en/. Accessed June 3, 2015.

4. Petersen L, Hayes EB. West nile virus in the Americas. Med Clin North Am. 2008;92(6):1307-22. ix.

5. Toé K, Jones CM, N'Fale S, Ismail HM, Dabiré RK, Ranson H. Increased pyrethroid resistance in malaria vectors and decreased bed net effectiveness, Burkina Faso. Emerg Infect Dis. 2014;20(10):1691-6.

6. Ranson H, N'guessan R, Lines J, Moiroux N, Nkuni Z, Corbel V. Prethroid resistance in African anopheline mosquitoes: what are the implications for malaria control? Trends Parasitol. 2011;27(2):91-8.

7. Hemingway $\mathrm{J}$. The role of vector control in stopping the transmission of malaria: Threats and opportunities. Philos Trans R Soc Lond B Biol Sci. 2014;369(1645):20130431.

8. Hemingway J, Field L, Vontas J. An overview of insecticide resistance. Science. 2002;298:96-7.

9. Kelvin A. Outbreak of Chikungunya in the Republic of Congo and the global picture. J Infect Dev Ctries. 2011;5:441-4.

10. Andriessen R, Snetselaar J, Suer RA, Osinga AJ, Deschietere J, Lyimo IN, Mnyone LL, Brooke BD, Ranson H, Knols BG, Farenhorst M. Electrostatic coating enhances bioavailability of insecticides and breaks pyrethroid resistance in mosquitoes. Proc Natl Acad Sci U S A. 2015;112(39):12081-6.

11. Liu N. Insecticide Resistance in Mosquitoes: Impact, Mechanisms, and Research Directions. Annu Rev Entomol. 2015;60(1):537-59.

12. David J, Strode C, Vontas J, Nikou D, Vaughan A, Pignatelli PM, Louis C, Hemingway J, Ranson H. The Anopheles gambiae detoxification chip: A highly specific microarray to study metabolic-based 
insecticide resistance in malaria vectors. Proc Natl Acad Sci U S A. 2005;102(11):4080-4.

13. Komagata $\mathrm{O}$, Kasai S, Tomita T. Overexpression of cytochrome P450 genes in pyrethroid-resistant Culex quinquefasciatus. Insect Biochem Mol Biol. 2010;40(2):146-52.

14. Gregory R, Darby AC, Irving H, Coulibaly MB, Hughes M, Koekemoer LL, Coetzee M, Ranson H, Hemingway J, Hall N, Wondji CS. A De Novo Expression Profiling of Anopheles funestus, Malaria Vector in Africa, Using 454 Pyrosequencing. PLoS ONE. 2011;6(2):e17418.

15. Reid WR, Zhang L, Liu F, Liu N. The Transcriptome Profile of the Mosquito Culex quinquefasciatus following Permethrin Selection. PLoS ONE. 2012;7(10):e47163.

16. Martinez-Torres D, Chandre F, Williamson MS, Darriet F, Bergé JB, Devonshire AL, Guillet P, Pasteur N, Pauron D. Molecular characterization of pyrethroid knockdown resistance (kdr) in the major malaria vector Anopheles gambiae s.s. Insect Mol Biol. 1998;7(2):179-84.

17. Ranson H, Jensen B, Vulule JM, Wang X, Hemingway J, Collins FH. Identification of a point mutation in the voltage-gated sodium channel gene of Kenyan Anopheles gambiae associated with resistance to DDT and pyrethroids. Insect Mol Biol. 2000;9(5):491-7.

18. Weill M, Malcolm C, Chandre F, Mogensen K, Berthomieu A, Marquine M, Raymond M. The unique mutation in ace-1 giving high insecticide resistance is easily detectable in mosquito vectors. Insect Mol Biol. 2004;13(1):1-7.

19. Du W, Awolola TS, Howell P, Koekemoer LL, Brooke BD, Benedict MQ, Coetzee M, Zheng L. Independent mutations in the Rdl locus confer dieldrin resistance to Anopheles gambiae and An. arabiensis. Insect Mol Biol. 2005;14(2):179-83.

20. Kasai S, Ng LC, Lam-Phua SG, Tang CS, Itokawa K, Komagata O, Kobayashi M, Tomita T. First detection of a putative knockdown resistance gene in major mosquito vector, Aedes albopictus. Jpn J Infect Dis. 2011;64(3):217-21.

21. Martinez-Torres D, Chevillon C, Brun-Barale A, Bergé JB, Pasteur N, Pauron D. Voltage-dependent Na + channels in pyrethroid-resistant Culex pipiens mosquitoes. Pestic Sci. 1999;55:1012-20.

22. Hemingway J, Hawkes NJ, McCarroll L, Ranson H. The molecular basis of insecticide resistance in mosquitoes. Insect Biochem Mol Biol. 2004;34:653-65.

23. Nardini L, Christian RN, Coetzer N, Koekemoer LL. DDT and pyrethroid resistance in Anopheles arabiensis from South Africa. Parasit Vectors. 2013;6(1):229.

24. Liu N, Li T, Reid WR, Yang T, Zhang L. Multiple Cytochrome P450 genes: their constitutive overexpression and permethrin induction in insecticide resistant mosquitoes, Culex quinquefasciatus. PLoS ONE. 2011;6(8):e23403.

25. Lumjuan N, Rajatileka S, Changsom D, Wicheer J, Leelapat P, Prapanthadara LA, Somboon P, Lycett $\mathrm{G}$, Ranson $\mathrm{H}$. The role of the Aedes aegypti Epsilon glutathione transferases in conferring resistance to DDT and pyrethroid insecticides. Insect Biochem Mol Biol. 2011;41(3):203-9.

26. Antonio-Nkondjio CPR, Tene BF, Kopya E, Costantini C, Awono-Ambene P, Wondji C. Investigation of mechanisms of bendiocarb resistance in Anopheles gambiae populations from the city of Yaoundé, Cameroon. Malar J. 2016;15(1):424. 
27. Nkya T, Akhouayri I, Kisinza W, David JP. Impact of environment on mosquito response to pyrethroid insecticides: facts, evidences and prospects. Insect Biochem Mol Biol. 2013;43:407-16.

28. Arensburger P, Megy K, Waterhouse RM, Abrudan J, Amedeo P, Antelo B, Bartholomay L, Bidwell S, Caler E, Camara F, Campbell CL, Campbell KS, Casola C, Castro MT, Chandramouliswaran I, Chapman SB, Christley S, Costas J, Eisenstadt E, Feschotte C, Fraser-Liggett C, Guigo R, Haas B, Hammond M, Hansson BS, Hemingway J, Hill SR, Howarth C, Ignell R, Kennedy RC, Kodira CD, Lobo NF, Mao C, Mayhew G, Michel K, Mori A, Liu N, Naveira H, Nene V, Nguyen N, Pearson MD, Pritham EJ, Puiu D, Qi Y, Ranson H, Ribeiro JM, Roberston HM, Severson DW, Shumway M, Stanke M, Strausberg RL, Sun C, Sutton G, Tu ZJ, Tubio JM, Unger MF, Vanlandingham DL, Vilella AJ, White O, White JR, Wondji CS, Wortman J, Zdobnov EM, Birren B, Christensen BM, Collins FH, Cornel A, Dimopoulos G, Hannick LI, Higgs S, Lanzaro GC, Lawson D, Lee NH, Muskavitch MA, Raikhel AS, Atkinson PW.: Sequencing of Culex quinquefasciatus establishes a platform for mosquito comparative genomics. Science 2010, 330(6000):86-88.

29. Holt R, Subramanian GM, Halpern A, Sutton GG, Charlab R, Nusskern DR, Wincker P, Clark AG, Ribeiro JM, Wides R, Salzberg SL, Loftus B, Yandell M, Majoros WH, Rusch DB, Lai Z, Kraft CL, Abril JF, Anthouard V, Arensburger P, Atkinson PW, Baden H, de Berardinis V, Baldwin D, Benes V, Biedler J, Blass C, Bolanos R, Boscus D, Barnstead M. The genome sequence of the malaria mosquito Anopheles gambiae. Science. 2002;298(5591):129-49.

30. Nene V, Wortman JR, Lawson D, Haas B, Kodira C, Tu ZJ, Loftus B, Xi Z, Megy K, Grabherr M, Ren Q, Zdobnov EM, Lobo NF, Campbell KS, Brown SE, Bonaldo MF, Zhu J, Sinkins SP, Hogenkamp DG, Amedeo P, Arensburger P, Atkinson PW, Bidwell S, Biedler J, Birney Megy K, Grabherr M, Ren Q, Zdobnov EM, Lobo NF, Campbell KS, Brown SE, Bonaldo MF, Zhu J, Sinkins SP, Hogenkamp DG, Amedeo P, Arensburger P, Atkinson PW, Bidwell S, Biedler J, Birney E, Bruggner RV, Costas J, Coy MR, Crabtree J, Crawford M, et al:: Genome sequence of Aedes aegypti, a major arbovirus vector. Science 2007, 316(5832):1718-1723.

31. David J, Ismail HM, Chandor-Proust A, Paine MJ. Role of cytochrome P450s in insecticide resistance: impact on the control of mosquito-borne diseases and use of insecticides on Earth. Philos Trans $R$ Soc Lond B Biol Sci. 2013;368(1612):20120429.

32. Djegbe I, Cornelie S, Rossignol M, Demettre E, Seveno M, Remoue F, Corbel V. Differential expression of salivary proteins between susceptible and insecticide-resistant mosquitoes of Culex quinquefasciatus. PLoS ONE. 2011;6(3):e17496.

33. Sun L, Ye Y, Sun H, Yu J, Zhang L, Sun Y, Zhang D, Ma L, Shen B, Zhu C. Identification of proteasome subunit beta type 6 (PSMB6) associated with deltamethrin resistance in mosquitoes by proteomic and bioassay analyses. PLoS ONE. 2013;8(6):e65859.

34. Wang W, Lv Y, Fang F, Hong S, Guo Q, Hu S, Zou F, Shi L, Lei Z, Ma K, Zhou D, Zhang D, Sun Y, Ma L, Shen B, Zhu C. Identification of proteins associated with pyrethroid resistance by iTRAQ-based quantitative proteomic analysis in Culex pipiens pallens. Parasit Vectors. 2015;8:95.

35. Gan C, Chong PK, Pham TK, Wright PC. Technical, experimental, and biological variations in isobaric tags for relative and absolute quantitation (iTRAQ). J Proteome Res. 2007;6(2):821-7. 
36. Wan C, Hao Z, Feng X. Structures, properties, and energy-storage mechanisms of the semi-lunar process cuticles in locusts. Sci Rep. 2016;6:35219.

37. Vannini L, Reed TW, Willis JH. Temporal and spatial expression of cuticular proteins of Anopheles gambiae implicated in insecticide resistance or differentiation of $\mathrm{M} / \mathrm{S}$ incipient species. Parasit Vectors 2014, 7(24).

38. Andersen S, Højrup P, Roepstorff P. Insect cuticular proteins. Insect Biochem Mol Biol. 1995;25(2):153-76.

39. Koganemaru R, Miller DM, Adelman ZN. Robust cuticular penetration resistance in the common bed bug (Cimex lectularius L.) correlates with increased steady-state transcript levels of CPR-type cuticle protein genes. Pestic Biochem Physiol. 2013;106:190-7.

40. Cornman RS, Willis JH. Annotation and analysis of low-complexity protein families of Anopheles gambiaethat are associated with cuticle. Insect Mol Biol. 2009;18(5):607-22.

41. Vontas J, David JP, Nikou D, Hemingway J, Christophides GK, Louis C, Ranson H. Transcriptional analysis of insecticide resistance in Anopheles stephensi using cross-species microarray hybridization. Insect Mol Biol. 2007;16(3):315-24.

42. Mamidala P, Wijeratne AJ, Wijeratne S, Kornacker K, Sudhamalla B, Rivera-Vega LJ, Hoelmer A, Meulia T, Jones SC, Mittapalli O. RNA-Seq and molecular docking reveal multi-level pesticide resistance in the bed bug. BMC Genomics 2012, 13(6).

43. Zhu F, Gujar H, Gordon JR, Haynes KF, Potter MF, Palli SR. Bed bugs evolved unique adaptive strategy to resist pyrethroid insecticides. Sci Rep 2013, 3(1456.).

44. Awolola T, Oduola OA, Strode C, Koekemoer LL, Brooke B, Ranson H. Evidence of multiple pyrethroid resistance mechanisms in the malaria vector Anopheles gambiae sensu stricto from Nigeria. Trans $\mathrm{R}$ Soc Trop Med Hyg. 2009;103(11):1139-45.

45. Stone B, Brown AW. Mechanisms of resistance to fenthion in Culex pipiens fatigans Wied. Bull World Health Organ. 1969;40:401-8.

46. Apperson C, Georghiou GP. Mechanisms of resistance to organophosphorus insecticides in Culex tarsalis. J Econ Entomol. 1975;68:153-7.

47. Wood O, Hanrahan S, Coetzee M, Koekemoer L, Brooke B. Cuticle thickening associated with pyrethroid resistance in the major malaria vector Anopheles funestus. Parasit Vectors. 2010;3(1):67.

48. DeVries D, Georghiou GP. Decreased nerve sensitivity and decreased cuticular penetration as mechanisms of resistance to pyrethroids in a (1R)-trans-permethrin-selected strain of the housefly. Pestic Biochem Physiol. 1981;15:231-4.

49. Wu D, Scharf ME, Neal JJ, Suiter DR, Bennett GW. Mechanisms of fenvalerate resistance in the German cockroach, Blattella germanica (L). Pestic Biochem Physiol. 1998;61:53-62.

50. Vatandoost $\mathrm{H}$ : The functional basis of pyrethroid resistance in the malaria vector, Anopheles stephensi. PhD Thesis, University of Liverpool, UK 1996. 
51. Balabanidou V, Kampouraki A, MacLean M, Blomquist GJ, Tittiger C, Juárez MP, Mijailovsky SJ, Chalepakis G, Anthousi A, Lynd A, Antoine S, Hemingway J, Ranson H, Lycett GJ, Vontas J. Cytochrome $\mathrm{P} 450$ associated with insecticide resistance catalyzes cuticular hydrocarbon production in Anopheles gambiae. Proc Natl Acad Sci U S A. 2016;113(33):9268-73.

52. Simma E, Dermauw W, Balabanidou V, Snoeck S, Bryon A, Clark RM, Yewhalaw D, Vontas J, Duchateau L, Van Leeuwen T. Genome-wide gene expression profiling reveals that cuticle alterations and P450 detoxification are associated with deltamethrin and DDT resistance in Anopheles arabiensis populations from Ethiopia. Pest Manag Sci. 2019;75:1808-18.

53. Hemingway J, Ranson $\mathrm{H}$. Insecticide resistance in insect vectors of human disease. Annu Rev Entomol. 2000;45:371-91.

54. Feyereisen R. Insect P450 enzymes. Annu Rev Entomol. 1999;44:507-33.

55. Chandor-Proust A, Bibby J, Régent-Kloeckner M, Roux J, Guittard-Crilat E, Poupardin R, Riaz MA, Paine M, Dauphin-Villemant C, Reynaud S, David JP. The central role of mosquito cytochrome P450 CYP6Zs in insecticide detoxification revealed by functional expression and structural modelling. Biochem J. 2013;455(1):75-85.

56. Yang T, Liu N. Genome Analysis of Cytochrome P450s and Their Expression Profiles in Insecticide Resistant Mosquitoes, Culex quinquefasciatus. PLoS ONE. 2011;6(12):e29418.

57. Kasai S, Weerashinghe IS, Shono T, Yamakawa M. Molecular Cloning, Nucleotide Sequence and Gene Expression of a Cytochrome P450 (CYP6F1) From the Pyrethroid-Resistant Mosquito, Culex Quinquefasciatus Say. Insect Biochem Mol Biol. 2000;30(2):163-71.

58. Kasai S, Weerashinghe IS, Shono T. P450 monooxygenases are an important mechanism of permethrin resistance in Culex quinquefasciatus Say larvae. Arch Insect Biochem Physiol. 1998;37:47-56.

59. Nahlen B, Clark JP, Alnwick D. Insecticide treated bed nets. Am J Trop Med Hyg. 2003;68:1-2.

60. Brooke B, Kloke G, Hunt RH, Koekemoer LL, Temu EA, Taylor ME, Small G, Hemingway J, Coetzee M. Bioassay and biochemical analyses of insecticide resistance in southern African Anopheles funestus (Diptera: Culicidae). Bull Entomol Res. 2007;91(04):265-72.

61. Vulule J, Beach RF, Atieli FK, McAllister JC, Brogdon WG, Roberts JM, Mwangi RW, Hawley WA. Elevated Oxidase and Esterase Levels Associated With Permethrin Tolerance in Anopheles Gambiae From Kenyan Villages Using Permethrin-Impregnated Nets. Med Vet Entomol. 1999;13(3):239-44.

62. Etang J, Chandre F, Guillet P, Manga L. Reduced bio-efficacy of permethrin EC impregnated bednets against an Anopheles gambiae strain with oxidase-based pyrethroid tolerance. Malar J. 2004;3(1):46.

63. Wondji C, Irving H, Morgan J, Lobo NF, Collins FH, Hunt RH, Coetzee M, Hemingway J, Ranson H. Two duplicated P450 genes are associated with pyrethroid resistance in Anopheles funestus, a major malaria vector. enome Res. 2008;19(3):452-9.

64. Amenya D, Naguran R, Lo TC, Ranson H, Spillings BL, Wood OR, Brooke BD, Coetzee M, Koekemoer LL. Over Expression of a Cytochrome P450 (CYP6P9) in a Major African Malaria Vector, Anopheles 
Funestus, Resistant to Pyrethroids. Insect Mol Biol. 2008;17(1):19-25.

65. Matambo T, Paine MJ, Coetzee M, Koekemoer LL. Sequence characterization of cytochrome P450 CYP6P9 in pyrethroid resistant and susceptible Anopheles funestus (Diptera: Culicidae). Genet Mol Res. 2010;9(1):554-64.

66. Djouaka R, Bakare AA, Coulibaly ON, Akogbeto MC, Ranson H, Hemingway J, Strode C. Expression of the cytochrome P450s, CYP6P3 and CYP6M2 are significantly elevated in multiple pyrethroid resistant populations of Anopheles gambiae s.s. from Southern Benin and Nigeria. BMC Genom. 2008;9(1):538.

67. Müller P, Warr E, Stevenson BJ, Pignatelli PM, Morgan JC, Steven A, Yawson AE, Mitchell SN, Ranson $\mathrm{H}$, Hemingway J, Paine MJ, Donnelly MJ. Field-Caught Permethrin-Resistant Anopheles gambiae Overexpress CYP6P3, a P450 That Metabolises Pyrethroids. PLoS Genet. 2008;4(11):e1000286.

68. Karatolos N, Pauchet Y, Wilkinson P, Chauhan R, Denholm I, Gorman K, Nelson DR, Bass C, ffrenchConstant RH, Williamson MS. Pyrosequencing the transcriptome of the greenhouse whitefly, Trialeurodes vaporariorum reveals multiple transcripts encoding insecticide targets and detoxifying enzymes. BMC Genomics 2011, 12(1).

69. Pauchet Y, Wilkinson P, Vogel H, Nelson DR, Reynolds SE, Heckel DG, ffrench-Constant RH. Pyrosequencing the Manduca sextalarval midgut transcriptome: messages for digestion, detoxification and defence. Insect Mol Biol. 2010;19(1):61-75.

70. Karunker I, Benting J, Lueke B, Ponge T, Nauen R, Roditakis E, Vontas J, Gorman K, Denholm I, Morin S. Over-expression of cytochrome P450 CYP6CM1 is associated with high resistance to imidacloprid in the B and Q biotypes of Bemisia tabaci (Hemiptera: Aleyrodidae). Insect Biochem Mol Biol. 2008;38(6):634-44.

71. Puinean A, Foster SP, Oliphant L, Denholm I, Field LM, Millar NS, Williamson MS, Bass C. Amplification of a Cytochrome P450 Gene Is Associated with Resistance to Neonicotinoid Insecticides in the Aphid Myzus persicae. PLoS Genet. 2010;6(6):e1000999.

72. Feyereisen R. Insect P450 inhibitors and insecticides: challenges and opportunities. Pest Manag Sci. 2015;71(6):793-800.

73. Reed J, Vanderwel D, Choi S, Pomonis JG, Reitz RC, Blomquist GJ. Unusual mechanism of hydrocarbon formation in the housefly: cytochrome P450 converts aldehyde to the sex pheromone component (Z)-9-tricosene and C02. Proc Natl Acad Sci U S A. 1994;91(21):10000-4.

74. Qiu Y, Tittiger C, Wicker-Thomas C, Le Goff G, Young S, Wajnberg E, Fricaux T, Taquet N, Blomquist GJ, Feyereisen R. An insect-specific P450 oxidative decarbonylase for cuticular hydrocarbon biosynthesis. Proc Natl Acad Sci U S A. 2012;109(37):14858-63.

75. Regard JB, Sato IT, Coughlin SR. Anatomical profiling of G protein coupled receptor expression. Cell. 2008;135:561-71.

76. Chen L, Zhong D, Zhang D, Shi L, Zhou G, Gong M, Zhou H, Sun Y, Ma L, He J, Hong S, Zhou D, Xiong C, Chen C, Zou P, Zhu C, Yan G. Molecular ecology of pyrethroid knockdown resistance in Culex pipiens pallens mosquitoes. PLoS ONE. 2010;5(7):e11681. 
77. Zhou D, Hao S, Sun Y, Chen L, Xiong C, Ma L, Zhang D, Hong S, Shi L, Gong M, Zhou H, Yu X, Shen B, Zhu C. Cloning and characterization of prophenoloxidase A3 (proPOA3) from Culex pipiens pallens. Comp Biochem Physiol B Biochem Mol Biol. 2012;162(4):57-65.

78. Shetty V, Sanil D, Shetty NJ. Insecticide susceptibility status in three medically important species of mosquitoes, Anopheles stephensi, Aedes aegypti and Culex quinquefasciatus, from Bruhat Bengaluru Mahanagara Palike, Karnataka, India. Pest Manag Sci. 2013;69:257-67.

79. WHO. International programme on chemical safety (IPCS): Microbial pest control agent Bacillus thuringiensis. Environmental Health Criteria. 1999;217:1-105.

80. Supek F, Bošnjak M, Škunca N, Šmuc T. REVIGO summarizes and visualizes long lists of gene ontology terms. PLOS ONE. 2011;6(7):e21800.

81. Kanehisa M, Goto S. KEGG Kyoto Encyclopedia of Genes and Genomes. Nucleic Acids Res. 2000;28(1):27-30.

82. Kanehisa M, Sato $Y$, Kawashima M, Furumichi M, Tanabe M. KEGG as a reference resource for gene and protein annotation. Nucleic Acids Res. 2016;44(D1):D457-62.

83. Kanehisa M, Furumichi M, Tanabe M, Sato Y, Morishima K. KEGG: new perspectives on genomes, pathways, diseases and drugs. Nucleic Acids Res. 2017;45(D1):D353-61.

84. Szklarczyk D, Franceschini A, Kuhn M, Simonovic M, Roth A, Minguez P, Doerks T, Stark M, Muller J, Bork P, Jensen LJ, von Mering C. The STRING database in 2011: functional interaction networks of proteins, globally integrated and scored. Nucleic Acids Res. 2011;39:D561-8.

85. Lopes C, Franz M, Kazi F, Donaldson SL, Morris Q, Bader GD. Cytoscape Web: an interactive webbased network browser. Bioinformatics. 2010;26(18):2347-8.

86. Wang W, Zhou H, Lin H, Roy S, Shaler TA, Hill LR, Norton S, Kumar P, Anderle M, Becker CH. Quantification of proteins and metabolites by mass spectrometry without isotopic labeling or spiked standards. Anal Chem. 2003;75:4818-26.

87. MacLean B, Tomazela DM, Shulman N, Chambers M, Finney GL, Frewen B, Kern R, Tabb DL, Liebler DC, MacCoss MJ. Skyline: an open source document editor for creating and analyzing targeted proteomics experiments. Bioinformatics. 2010;26:966-8.

\section{Table}

Table 1 Resistance levels after insecticide selection 


\begin{tabular}{|lllll|}
\hline Insecticide & strain & LC50(ppm) & Regression equation & R/S \\
\hline Cypermethrin & susceptible & 0.000120 & $\mathrm{Y}=7.6256+2.8696 \mathrm{x}$ & 1.00 \\
\cline { 2 - 5 } & Cx_cym & 0.029160 & $\mathrm{Y}=-1.4591+4.4096 \mathrm{x}$ & 243.00 \\
\hline Propoxur & susceptible & 0.1135 & $\mathrm{Y}=7.6650+2.9986 \mathrm{x}$ & 1.00 \\
\cline { 2 - 5 } & Cx_pro & 1.2867 & $\mathrm{Y}=4.5268+4.5843 \mathrm{x}$ & 11.34 \\
\hline DDV & susceptible & 0.0954 & $\mathrm{Y}=7.2198+2.1750 \mathrm{x}$ & 1.00 \\
& Cx_ddv & 0.7792 & $\mathrm{Y}=5.7400+6.8493 \mathrm{x}$ & 8.17 \\
\hline
\end{tabular}

Note: Resistance ratios were computed from LC50 values as compared to the susceptible parental strain. Resistance ratios with confidence intervals not overlapping the value of 1 are shown in bold.

\section{Description Of Additional Files}

Additional file1 Table S1: Global protein profiles among insecticide selected of Culex pipiens pallens using iTRAQ.

\section{Additional file 2 Figure S1-S8}

Figure S1: Annotated KEGG map for oxidative phosphorylation, map00190

The blue border belongs to the background protein, and the black border indicates the protein was not identified in this experiment. The red/green colour in the figure marks the differentially expressed proteins detected in this experiment, in which red represents upregulated proteins and green represents downregulated proteins. Half red and half green indicates the protein is both upregulated and downregulated (the same meaning as in this manuscript).

Figure S2: Annotated KEGG map for Ribosome, map03010

Figure S3: PPI networks analysis of altered proteins in Cx_cym vs. Cx_s in Cx. pipiens pallens

Figure S4: PPI networks analysis of altered proteins in Cx_pro vs. Cx_s in Cx. Pipiens pallens

Figure S5: COG classification of differentially expression proteins

559 proteins were assigned to 15 COG categories, and the " $\mathrm{J}$ " cluster (translation, ribosomal structure and biogenesis) and "Z" cluster (cytoskeleton ) represent the largest two groups.

Figure S6: All_Enrich Treemap in Cx_bti vs. Cx_nbti (biological process).

The five most enriched GO terms proteins biosynthetic process, microtubule-based process, organic substance biosynthetic process, organonitrogen compound metabolic process, oxidoreduction coenzyme 
metabolic process

Figure S7: All_Enrich Treemap in Cx_bti vs. Cx_nbti (molecular function). Structural molecule activity, structural constituent of cytoskeleton are the most enriched GO terms proteins

Figure S8: Visualization of significantly enriched Domain in Cx_bti vs. Cx_nbti.
A. Visualization of significantly enriched Domain in Cx_bti vs. Cx_nbti, B. Visualization of significantly enriched downregulation Domain in Cx_bti vs. Cx_nbti. Upregulated proteins in functional categorizations of proteins differentially expressed according to Fisher's extract test. The Number of Diffproteins is the number of differentially expressed proteins enriched in the Domain; the Domain enriched fold is shown on a $\log 2$ scale in a colour gradient.
Additional file 3 Table S2: PRM verification analysis differentially expression proteins under of insecticide selection

Additional file 4 Table S3: Differentially expression proteins identified in midgut of $\mathrm{Cx}$. pipiens pallens using iTRAQ.

\section{Figures}




\section{-log10(Fisher's exact $p$ value)}

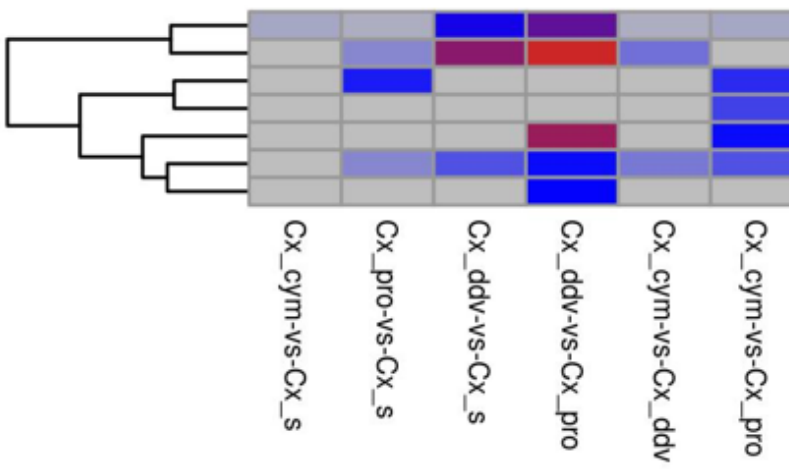

GO:0005198:structural molecule activity

GO:0042302:structural constituent of cuticle

GO:0008061:chitin binding

GO:0016746:transferase activity, transferring acyl .. GO:0005319:lipid transporter activity

GO:0005549:odorant binding

GO:0019843:rRNA binding

GO_MF $(\mathrm{p}<0.05)$ -log10(Fisher's exact p value)

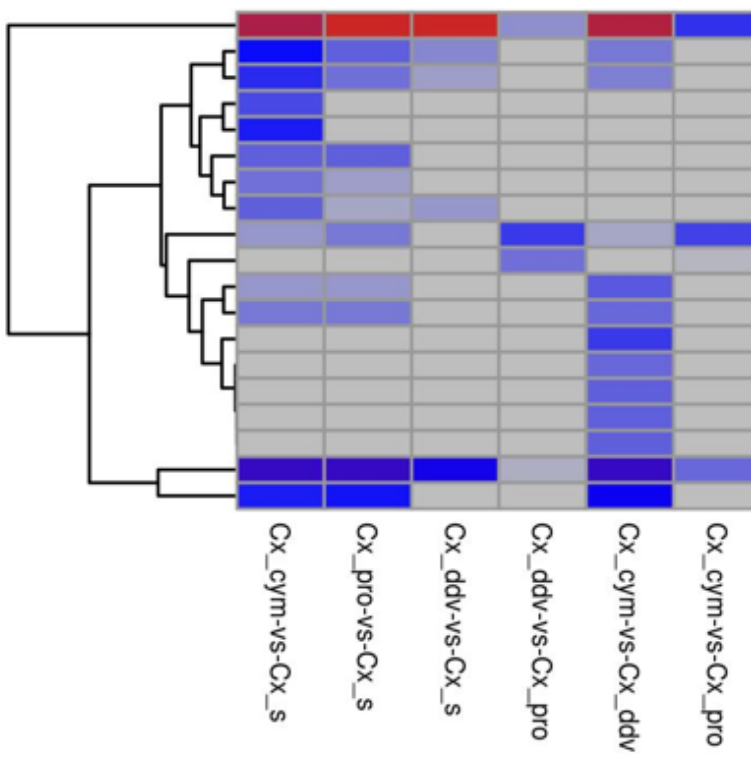

GO:0042302:structural constituent of cuticle GO:0022892:substrate-specific transporter activity GO:0005215:transporter activity GO:0016615:malate dehydrogenase activity GO:0030060:L-malate dehydrogenase activity GO:0019843:rRNA binding

GO:0008324:cation transmembrane transporter activit.. GO:0022891:substrate-specific transmembrane transpo... GO:0005549:odorant binding GO:0016740:transferase activity GO:0003774:motor activity GO:0003777:microtubule motor activity GO:0004843:thiol-dependent ubiquitin-specific prote. GO:0005200:structural constituent of cytoskeleton GO:0036459:thiol-dependent ubiquitinyl hydrolase ac... GO:0101005:ubiquitinyl hydrolase activity GO:0019783:ubiquitin-like protein-specific protease.. GO:0005198:structural molecule activity GO:0005319:lipid transporter activity

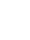




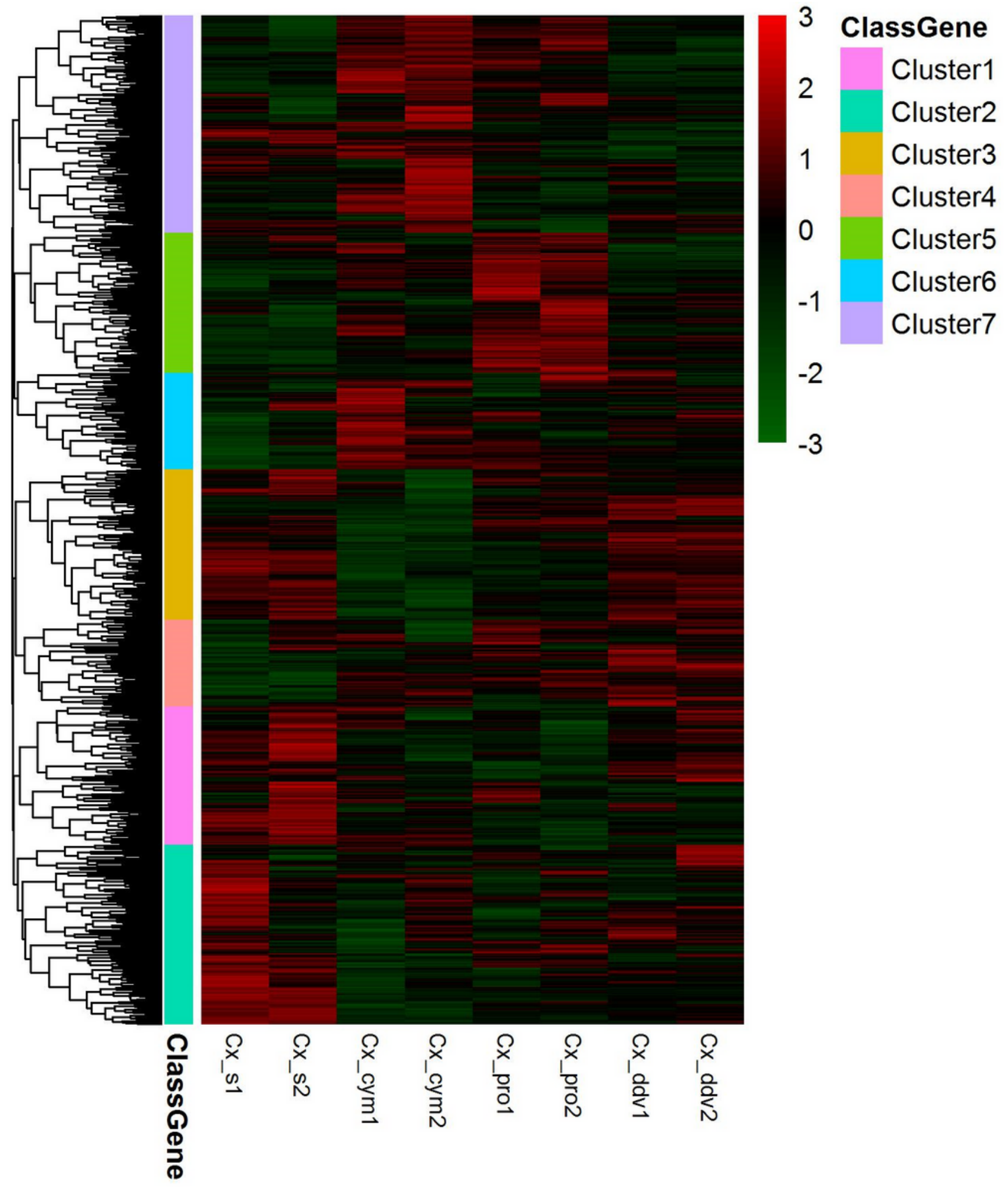

Figure 2

Clustering of protein expression patterns and functional enrichment. Differential protein relative expression matrix heatmap of the three insecticide resistance groups; the color in the figure indicates the relative expression level of the protein in the sample. The cluster of more abundantly expressed proteins is highlighted in red, and the green color represents a lower expression level, color bars represent specific 
expression abundance. The total number of observed spectra assigned to each protein in each insecticide selection was used as the basis for clustering.

A. Annotated KEGG map for Metabolism of xenobiotics by cytochrome P450, map $00980^{41-43}$
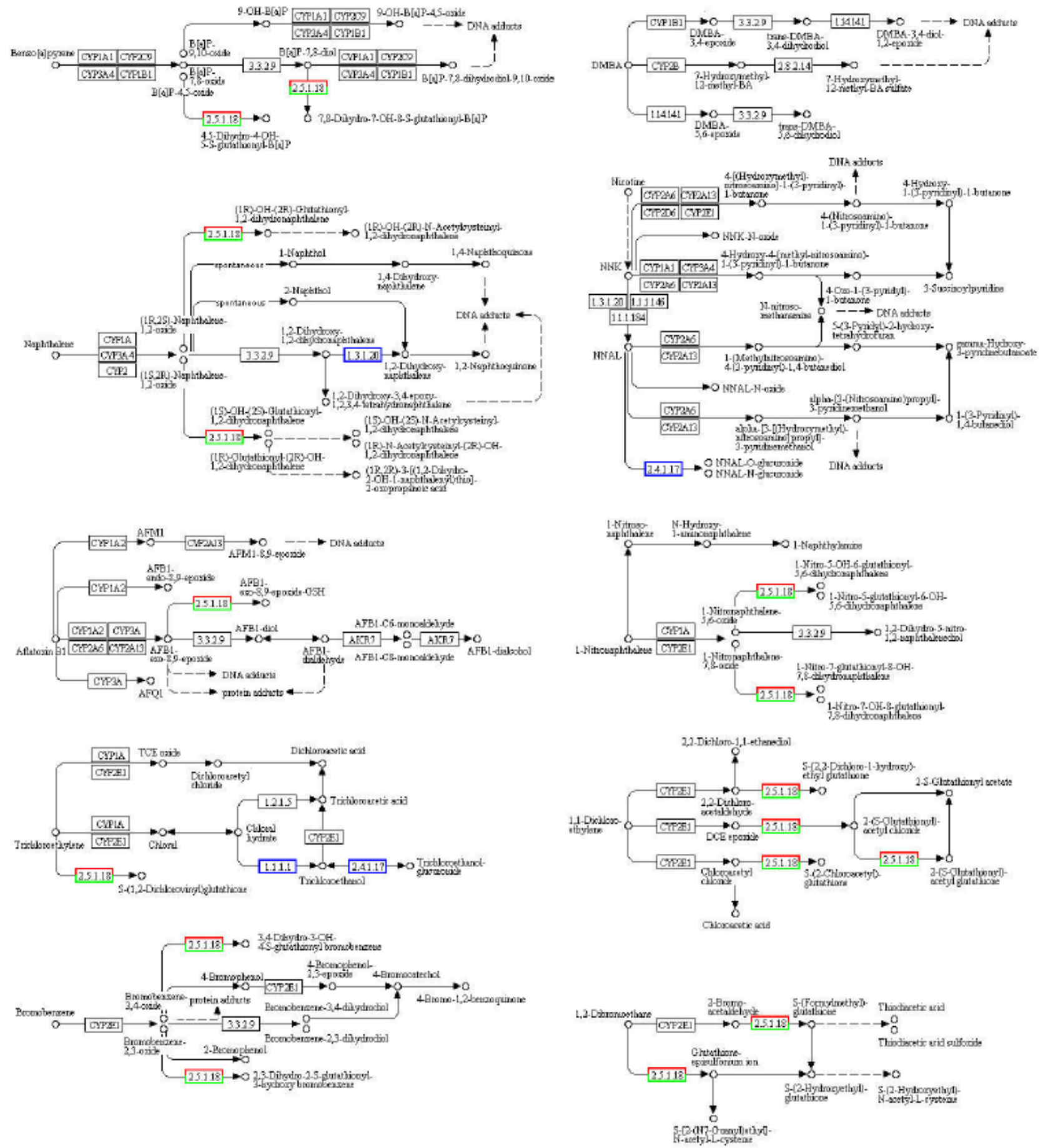

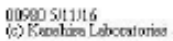

\section{Figure 3}

Representative KEGG pathway A: Representative KEGG metabolism of xenobiotics by cytochrome P450 pathway (map00980), B: Representative KEGG drug metabolism - cytochrome P450 pathway (map00982) The rectangular nodes in the figure represent gene products, the blue border belongs to the 
background proteins, and the white color indicates proteins not identified in this experiment. The $\mathrm{red} / \mathrm{green}$ colors in the figure indicate to the differentially expressed proteins detected in this study, with red representing upregulated proteins and green downregulated proteins. Half red and half green indicates both upregulated and downregulated proteins for that gene product.
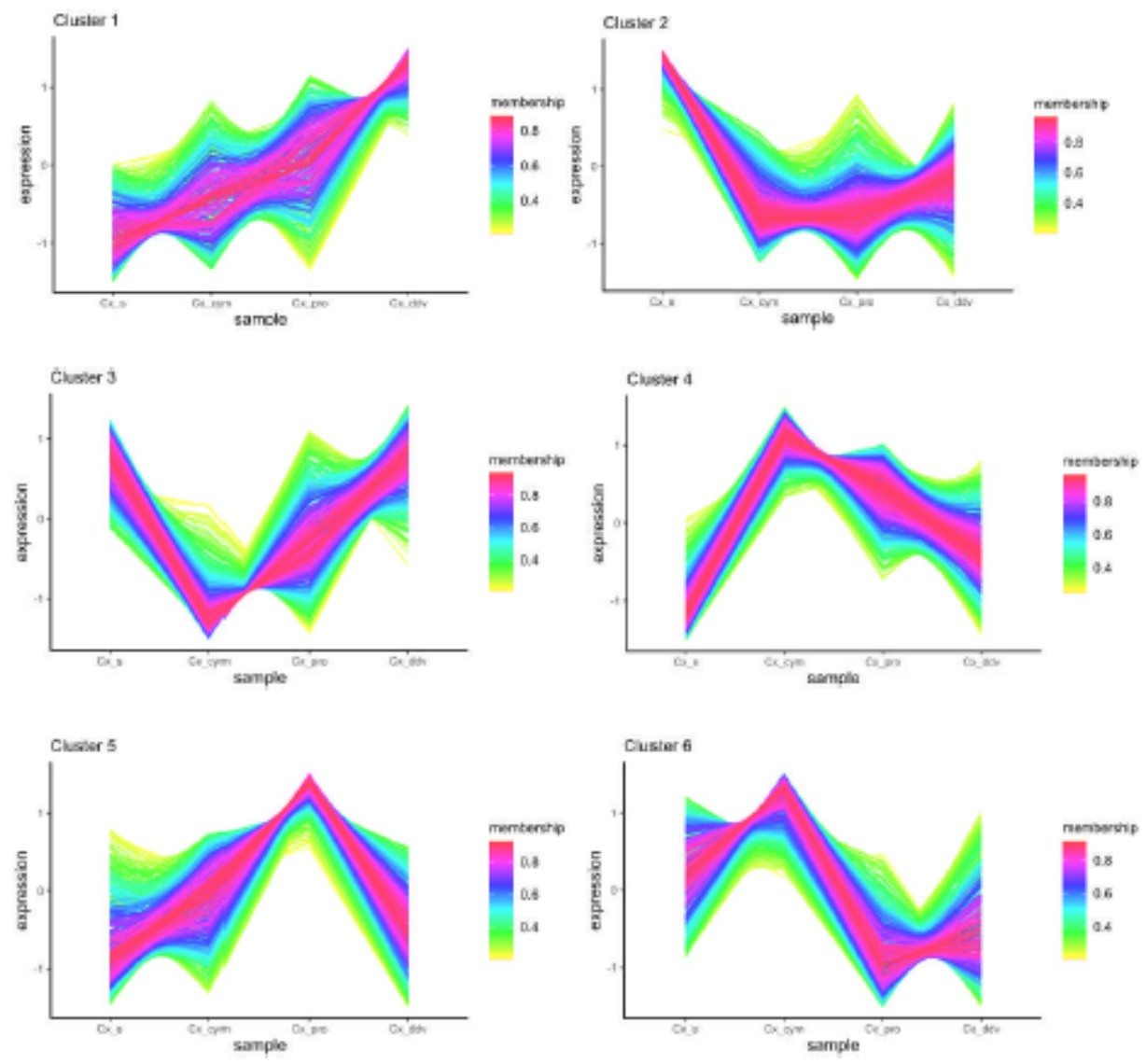

\section{Figure 4}

Comparison of protein expression pattern clusters between Cx_cym, Cx_pro, Cx_ddv and Cx_s in Cx. pipiens pallens For the expression trend line graph of each sub-cluster, the $x$-axis is the comparison sample group, and the $y$-axis is the relative expression level of the protein in the group of samples. Each line in the figure represents a protein, and the different color representations show the relationship between relative expression and the mean value. Each graph shows one type of expression pattern, a trend that reflects changes in the expression of this group of proteins. 3 

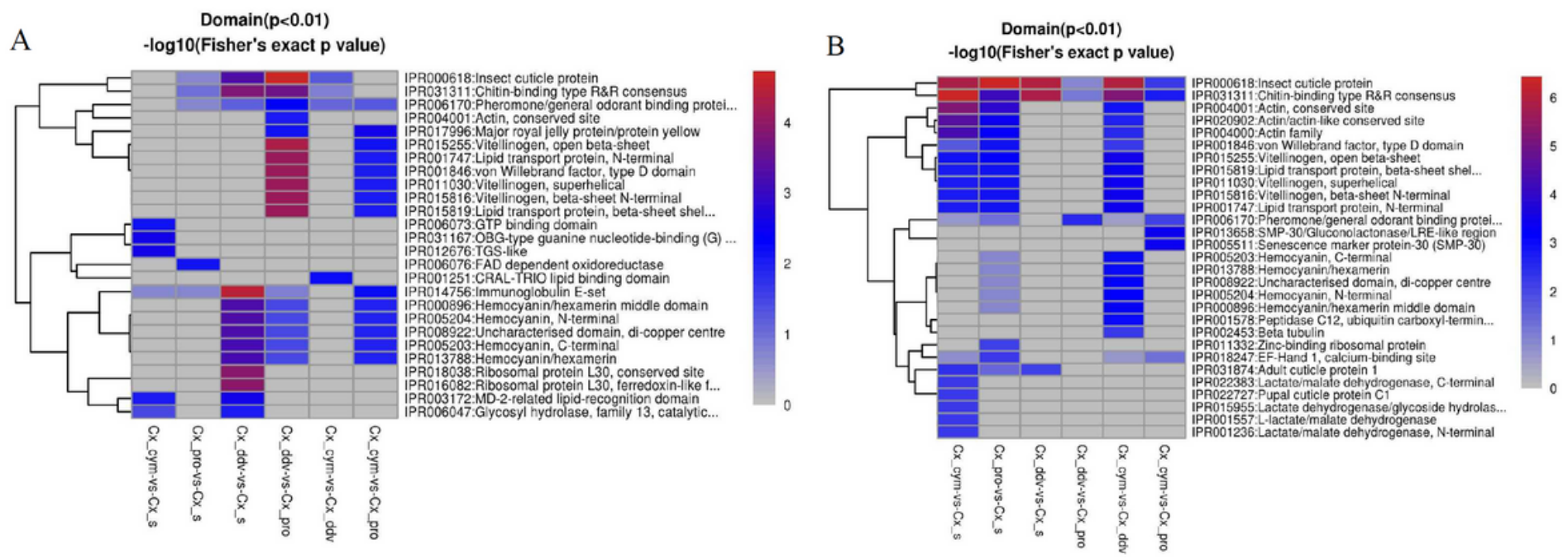

Figure 5

Functional enrichment-based clustering for protein groups in domain Clustering of the results of differential protein enrichment in different groups, the color -log10 (Fisher exact test $p$ value) represents the credibility of enrichment. A and B, Visualization of significantly enriched upregulation and downregulation Domain in Cx. pipiens pallens, respectively.
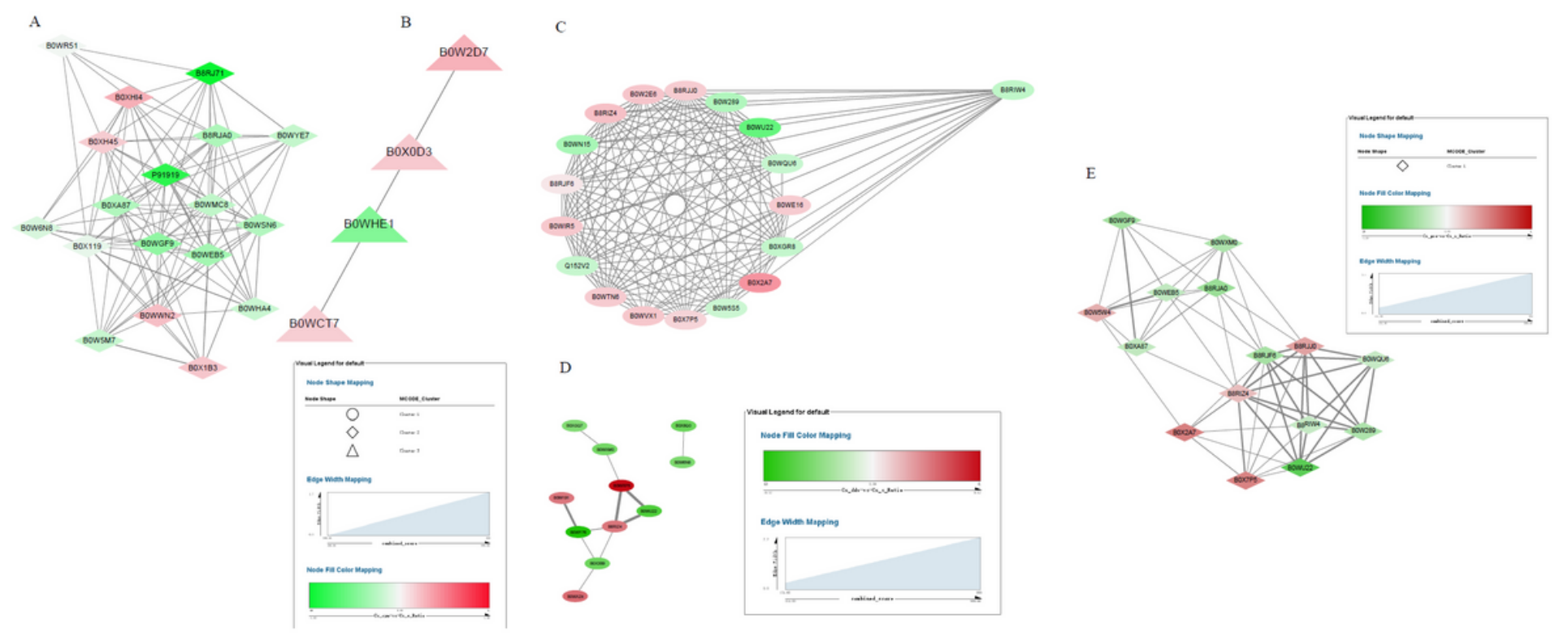

Figure 6

PPI networks analysis of altered proteins in $\mathrm{Cx}$. pipiens pallens after insecticide selection A-C, PPI networks analysis of altered proteins in Cx_cym vs. Cx_s in Cx. pipiens pallens D, PPI networks analysis of altered proteins in Cx_ddv vs. Cx_s in Cx. pipiens pallens E, PPI networks analysis of altered proteins in Cx_pro vs. Cx_s in Cx. pipiens pallens The interaction map of altered proteins under insecticide selection in Cx. pipiens pallens is illustrated as confidence view, each circle in the figure represents a protein, interaction between expressed proteins are indicated by the connecting line, where the thickness of the 
connecting lines indicates the level of confidence, stronger associations are represented by thicker lines. Network interaction analysis was performed using the STRING protein interaction prediction online software and was visualized using Cytoscape version 3.4

\section{Supplementary Files}

This is a list of supplementary files associated with this preprint. Click to download.

- Additionalfile1Tables1.xls

- Additionalfile2FiguresFigureS1S8.pdf

- Additionalfile3Tables2.xls

- Additionalfile4Tables3.xls 